\title{
Prevalence and distribution of the fabella: a radiographic study in Turkish subjects
}

\author{
O.F. Egerci ${ }^{1}$, O. Kose², A. Turan², O.F. Kilicaslan², R. Sekerci ${ }^{3}$, N. Keles-Celik ${ }^{3}$ \\ ${ }^{1}$ Orthopedics and Traumatology Department, Elmadag State Hospital, Ankara, Turkey \\ 2Orthopedics and Traumatology Department, Antalya Training and Research Hospital, Antalya, Turkey \\ ${ }^{3}$ Anatomy Department, Akdeniz University Medical Faculty, Antalya, Turkey \\ [Received: 10 August 2016; Accepted: 19 October 2016]
}

\begin{abstract}
Background: The purpose of this study is to examine the plain knee radiographs in Turkish subjects in order to determine the prevalence of the fabella and analyse the differences between age, gender, laterality and its symmetry pattern.

Materials and methods: Bilateral antero-posterior and lateral knee radiographs of 500 patients (250 male and 250 female subjects, 1000 knee radiographs) were randomly selected from the clinical database and retrospectively evaluated. Data on patient age, gender, and knee laterality (right-left) were evaluated from hospital records. The differences between the sesamoid bones at a particular location and the side, sex and age groups were analysed.

Results: The overall prevalence of the fabella (unilateral or bilateral) was $22.8 \%$ (114 subjects). The fabella was present unilaterally in 38 (7.6\%) subjects, while it was present bilaterally in 76 (15.2\%) subjects. The prevalence of the fabella was similar between the body sides. The prevalence of the fabella was also similar between genders (unilateral or bilateral cases) and age groups.

Conclusions: We examined the prevalence, symmetry pattern, age and gender differences in Turkish population. It is the first study performed on Turkish population with the largest sample in current literature. Prevalence of fabella is found to be $22.8 \%$ which is quite similar with other Caucasian ethnic populations. (Folia Morphol 2017; 76, 3: 478-483)
\end{abstract}

Key words: fabella, sesamum genu superius laterale, sesamoid bone, posterolateral knee pain, radiography

\section{INTRODUCTION}

Latin word 'Faba' means bean, bead, pellet or seed and '-ella' is a diminutive suffix, thus 'Fabella' means little bean or bead. The small sesamoid bone located in the posterolateral aspect of the knee at the insertion of lateral gastrocnemius muscle is named as fabella (sesamum genu superius laterale) (Fig. 1) [7]. In majority of relevant studies, its location has been reported on the lateral head of gastrocnemius, but it is occasionally found in the medial head in few reports $[13,15,23,33,40]$. The size of the fabella is variable, changing from a tiny dot to a body with a width of $2.2 \mathrm{~cm}[16,25]$. It may be osseous and/ /or cartilaginous in nature, and articulates with the posterior aspect of lateral femoral condyle [15, 25]. The fabella is believed to be involved in the stabilisation of the posterolateral structures of the knee $[19,39,44]$. Its associated fabellofibular ligament is a structure formed through the thickening of the distal part of short head of the biceps femoris tendon [20].

Address for correspondence: Prof. Dr. N. Keles-Celık, Department of Anatomy, Akdeniz University Faculty of Medicine, 07070 Antalya, Turkey, tel: +90 (242) 2274485, fax: +90 (242) 2274485, e-mail: nigarc@akdeniz.edu.tr 


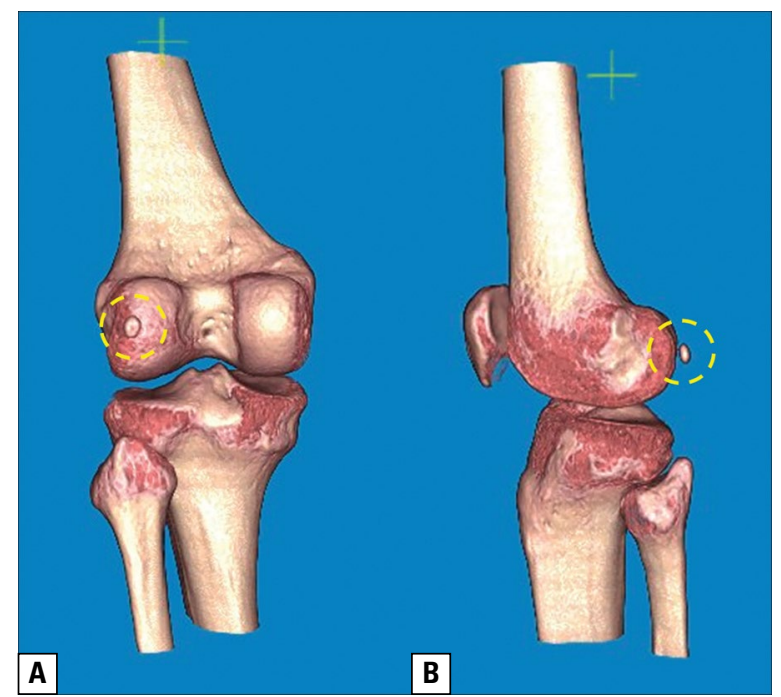

Figure 1. Posterior (A) and lateral (B) view of a patient with three-dimensional computed tomography. Yellow dotted circle indicates the fabella.

The functions of sesamoid bones are to modify pressure, to diminish friction thereby to protect the tendons, to change the direction of a muscle pull, and to assist muscle actions [21]. The fabella is usually observed in the gastrocnemius muscle of several mammals such as dogs, cats, and rabbits $[4,8,14$, $24,27]$. The larger size of the fabella in males than in females supports the notion that it assumes a biomechanical function [28]. In evolutionary terms, the fabella seemingly starts to disappear during the transition from the quadripedal posture to the bipedal [32], because the standing position requires more stability and less rotation [25, 32]. Thus, the fabella is variably absent in humans and classified as a phylogenetically retrogressive anatomical structure that lost its function with the upright of the human.

The fabella is usually detected in routine lateral knee radiographs without signifying a pathological lesion and accepted as a normal anatomic variant. On plain radiographs, it may be confused with intra-articular loose bodies or osteophytes in osteoarthritic knees and intra-meniscal calcifications $[22,25,30]$. The fabella syndrome is defined as a condition resulting in pain at the posterolateral corner of the knee; increased pain in the knee in full extension [41, 42]. Goldenberg and Wild [11] considered this painful syndrome in the posterolateral region of the knee as the chondromalacia of the fabella. The other clinical conditions include the osteoarthritis $[3,28]$, fractures $[6,17,39]$ and disclocations $[9,10]$ of the fabella. Pritchett et al. [28] proposed that the presence of the fabella increases the risk of knee osteoarthritis. It may lead to peroneal nerve compression due to its close anatomical association at the posterolateral corner of the knee [18, 36, 38]. In addition, Ando Yukari et al. [1] reported popliteal artery compression induced by the fabella. Although, presence or absence of the fabella is accepted as a normal variant, due to the above mentioned clinical conditions related with the fabella, clinicians should know a thorough knowledge about the anatomical characteristics and frequency of the fabella in population they practice.

As a conventional knowledge, the fabella is observed at a prevalence of $10-30 \%$ in the society and once identified, it is generally found on both knees $[7,10]$. However, there are studies in the literature that focus on the efforts to determine the prevalence of the fabella in various ethnic populations. These studies utilised one or more of the methods of radiography, magnetic resonance imaging (MRI) or cadaver dissection. In addition to the prevalence of the fabella, most of these studies addressed the age and gender differences, laterality and symmetry patterns. Results of these studies indicate that prevalence of the fabella is quite variable in different ethnic populations. Up to date, there is no study in the literature investigating the prevalence of the fabella in the Turkish population. The purpose of this study is to examine the plain knee radiographs in Turkish subjects in order to determine the prevalence of the fabella and analyse the differences between age, gender, laterality and its symmetry pattern.

\section{MATERIALS AND METHODS}

A retrospective study was designed using archival records on patients ( $>18$ years old) whom bilateral knee radiographs were taken between January 2015 and January 2016. All indications from picture archiving and communication systems and institutional clinical database. In this study, a total number of 500 patients (250 male and 250 female subjects, 1000 knee radiographs) were identified. Bilateral anteroposterior and lateral knee radiographs were randomly selected and included in this study. Patients with advanced osteoarthritis of the knee were also excluded if the posterior osteophytes and the fabella were not clearly discriminated. The present study was carried out according to the principles of the Declaration of Helsinki. 
Initially, two orthopaedic surgeons reviewed all radiographs and searched for the fabella in typical locations independently. Later, a final decision was reached with consensus on uncertain cases. Data on patient age, gender, and knee laterality (right-left) were evaluated from hospital records. Continuous variables were stated as mean and standard deviation and categorical variables as percentage and frequency distribution. The differences between the sesamoid bones at a particular location and the side, sex and age groups were analysed using Pearson $\chi^{2}$ test. A $p$-value $<0.05$ was considered statistically significant.

\section{RESULTS}

A total of 500 subjects ( 250 men and 250 women) aged between 18 and 90 years (mean age $56.7 \pm 14.2$ ) were examined. The overall prevalence of the fabella (unilateral or bilateral) was $22.8 \%$ (114 subjects). The fabella was present unilaterally in $38(7.6 \%)$ subjects, while it was present bilaterally in $76(15.2 \%)$ subjects (Fig. 2). The ratio of bilateral versus unilateral cases was 2:1. Among unilateral cases (38 subjects), 18 had fabella on the right side, 20 had on the left. The prevalence of the fabella was similar between the body sides $(p=0.746)$. The overall prevalence of the fabella (unilateral or bilateral) was $21.6 \%$ in men and $24.0 \%$ in women. Prevalence of the fabella between gender (unilateral or bilateral cases) were similar $(p=0.594)$. The summary of data is presented in Table 1. The whole study group was classified into age groups at an interval of ten years. The prevalence of the fabella between age groups were similar $(p=0.263$ ) (Table 2 ).

\section{DISCUSSION}

The fabella is usually detected in routine lateral knee radiographs without signifying a pathological lesion and accepted as a normal anatomic variant. On plain radiographs, it may be confused with intra-articu-

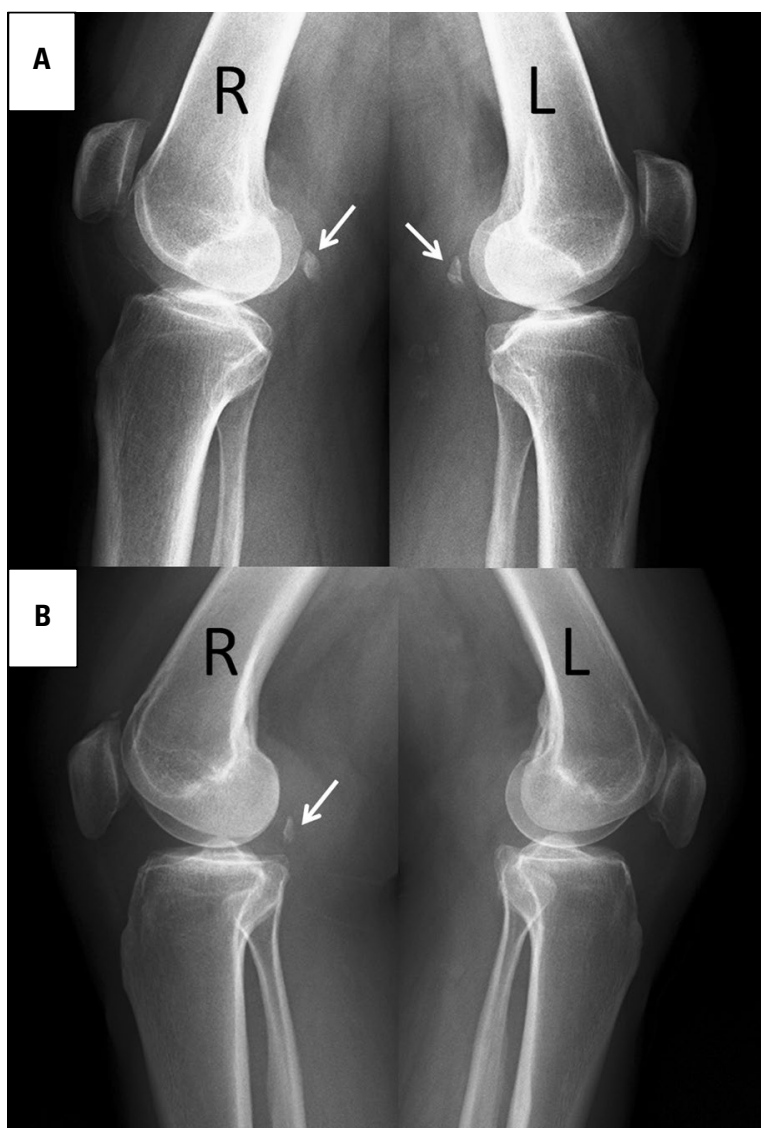

Figure 2. Bilateral (A) and unilateral (B) presence of the fabella in two different subjects (arrows showed os fabella); $\mathrm{R}$ - right side; $\mathrm{L}$ - left side.

lar loose bodies or osteophytes in osteoarthritic knees, intra-meniscal calcifications and cyamella (another sesamoid bone found within the popliteal tendon) [22, $25,30]$. Histological and anatomical features of clinical conditions associated with fabella to be addressed in previous studies $[5,34,41,42]$. This study is the largest radiographic studies in the literature.

There are few studies in current literature that investigates the frequency of the fabella among

Table 1. Detailed data of the study group

\begin{tabular}{lllccc}
\hline & & Both absent & Unilateral present & Both present \\
\hline Gender & Female & Count & 190 & 22 (11 right/11 left) & 38 \\
& & $\%$ within sex & $76.0 \%$ & $8.8 \%$ & $15.2 \%$ \\
\cline { 2 - 6 } & Male & Count & 196 & 16 (7 right/9 left) & 38 \\
& & $\%$ within sex & $78.4 \%$ & $6.4 \%$ & $15.2 \%$ \\
\hline Total & Count & 386 & 38 (18 right/20 left) & 76 \\
& & \% of total & $77.2 \%$ & $7.6 \%$ & $15.2 \%$ \\
\hline
\end{tabular}


Table 2. Prevalence of fabella among age groups

\begin{tabular}{lccc}
\hline $\begin{array}{l}\text { Age groups } \\
\text { [years] }\end{array}$ & Absent & $\begin{array}{c}\text { Present } \\
\text { (unilateral } \\
\text { or bilateral) }\end{array}$ & Total \\
\hline $18-25$ & 16 & 2 & 18 \\
$26-35$ & 24 & 2 & 26 \\
$36-45$ & 42 & 10 & 52 \\
$46-55$ & 88 & 30 & 118 \\
$56-65$ & 108 & 38 & 146 \\
$>65$ & 108 & 32 & 140 \\
\hline Total & 386 & 114 & 500 \\
\hline
\end{tabular}

different ethnic populations (Table 3). Generally reported these studies can be divided into two groups, i.e. studies performed in Far East countries in Asia and those performed in Western countries in Europe and America. The prevalence of the fabella in Turkish population $(22.8 \%)$ is compatible with the generally accepted range of 10-30\% and those studies conducted in Western countries. As an interesting finding, the prevalence of the fabella increases from west to east. Highest prevalence of the fabella has been reported in Japanese population (85.8\%) in current literature. However, almost all of these studies from Far East worked on cadavers. Cartilaginous fabella can easily be identified in cadaver dissections, whereas only sufficiently ossified fabella can be detected on plain radiographs. This may be a reason why radiographic studies reported lower prevalence of the fabella [19].

Zeng et al. [44] utilised cadaver dissection in combination with radiographic control and stated that they could only identified 8 out of 19 cartilaginous fabellae through radiographic images. Minowa et al. [19] grouped fabellae into rigid and elastic groups rather than osseous and cartilaginous and stated that 77 (36.3\%) out of 182 fabellae identified in 212 knees were an elastic structure. Then, they examined 33 of the rigid fabellae through histopathological means and indicated that 29 were osseous and 4 fibrotic in structure [19]. Kawashima et al. [15] worked on cadavers in their study and determined that 44 out of 99 fabellae osseous and 45 cartilaginous structures. On the other hand, Tabira et al. [35] observed 46 out of 75 fabellae to be osseous and 24 cartilaginous in terms of their structure. In another study conducted in Far East, Chew et al. [2] investigated the combination of MRI and radiography and established the prevalence of the fabella to be $31.25 \%$ and reported that all of these cases had an osseous structure (cartilaginous cases can be detected in MRI). This study originates from Singapore and identified the prevalence of the

Table 3. Previous studies on the prevalence of fabella

\begin{tabular}{|c|c|c|c|c|c|}
\hline Author [reference] & Year & Ethnic group & Method & $\begin{array}{l}\text { Number } \\
\text { of samples } \\
\text { (knees) }\end{array}$ & $\begin{array}{c}\text { Incidence } \\
(\%)\end{array}$ \\
\hline Kaplan [13] & 1961 & Caucasian (America) & Cadaver & 135 & 8.7 \\
\hline Takebe et al. [37] & 1983 & Asian (Japan) & Radiography & NR & 33.4 \\
\hline Pritchett [28] & 1984 & Caucasian (America) & Radiography & 153 & 15.0 \\
\hline Yu et al. [43] & 1996 & Caucasian (America) & MRI & 100 & 19.0 \\
\hline Sarin et al. [31] & 1999 & Caucasian (America) & Radiography & 112 & 31.3 \\
\hline Minowa et al. [19] & 2004 & Asian (Japan) & Cadaver & 212 & 85.8 \\
\hline Kawashima et al. [15] & 2007 & Asian (Japan) & Cadaver & 150 & 66.0 \\
\hline Raheem et al. [29] & 2007 & Caucasian (Ireland) & Cadaver & 22 & 9.1 \\
\hline Silva et al. [34] & 2010 & Caucasian (Brazil) & Cadaver & 62 & 3.1 \\
\hline Phukubye and Oyedele [25] & 2011 & Caucasian and African & Cadaver & 102 & 23.5 \\
\hline Piyawinijwong et al. [26] & 2012 & Asian (Thailand) & Cadaver & 187 & 50.5 \\
\hline Tabira et al. [35] & 2012 & Asian (Japan) & Cadaver & 102 & 68.6 \\
\hline Zeng et al. [44] & 2012 & Asian (China) & Cadaver and Radiography & 61 & 86.9 \\
\hline Chew et al. [2] & 2014 & Asian (Singapore) & Radiography and MRI & 80 & 31.25 \\
\hline Present study & 2016 & Caucasian (Turkey) & Radiography & 1000 & 22.8 \\
\hline
\end{tabular}

$\mathrm{MRI}$ — magnetic resonance imaging 
fabella to be lower than those specified in SouthEastern Asian studies. The argument supported by the authors with this conclusion is that most of the other studies originate from China and Japan where daily habits of these populations require a high number of knee movements (such as kneeling) and thus, lead to a higher prevalence of fabella cases.

The present study observed the fabella in 38 $(7.6 \%)$ cases and bilateral fabella in $76(15.2 \%)$ cases. Among the unilateral cases, 18 cases were on the right knee and 20 cases on the left knee with no differences identified between these groups. Phukubye et al. [25] failed to establish any difference between body sides. The prevalence of the fabella was determined to be $21.6 \%$ among men and $24.0 \%$ among women and no significant difference was observed in our study. The prevalences identified in other relevant studies for men and women have been $26.0 \%$ and $26.2 \%$ in lida et al. [12], $21.2 \%$ and $27.8 \%$ in Phukubye et al. [25] respectively. All of these studies observed similar frequencies in both gender like our findings. Based on our results and other studies, we may assume that the presence of the fabella is not associated with body side or sex.

There is conflicting findings among various studies regarding the frequency of the fabella in ageing population. According to some authors, prevalence of the fabella increases with age. lida et al. [12] argued that the prevalence of the fabella increased in proportion with age. Phukubye et al. [25] found higher prevalence of the fabella after the age of 90 . We established that there was not any difference among age groups in our study. Similarly Takebe et al. [37] and Tabira et al. [35] also failed to find any difference among age groups. During skeletal evolution, cartilaginous fabella may be ossified in later ages and detection may be easier on radiographic studies. However, this assumption can only explain a difference between children and adults. Unfortunately, there is no study comparing skeletally mature and immature samples. Thus, currently we cannot strongly claim that prevalence of the fabella changes between young and elderly subjects.

The present study has strong and weak features. Because of we investigated the patients' both knees; we could evaluate whether fabella exists bilaterally or not, and its symmetry patterns. Both genders with a broad age range were included, which allowed us to analyse age and gender dispersion. A large sample (1000 knees) was investigated to minimize the errors caused by the small sample size. On the other hand, only radiographic data was analysed apart from clinical and histopathological findings. Thus we don't know how many of these cases had symptomatic fabella. Because of the fact that radiographic studies may not allow the detection of a cartilaginous fabella, the results of this study represent only the prevalence of bony fabella.

\section{CONCLUSIONS}

As a conclusion, the present study examined the prevalence, symmetry pattern, age and gender differences in Turkish population. It is the first study performed on Turkish population with the largest sample in current literature. Prevalence of the fabella is found to be $22.8 \%$ which is quite similar with other Caucasian ethnic populations. In future, clinical studies outlining both radiographic and histopathologic characteristics of symptomatic fabella which helps surgeons to discriminate patients presenting with posterolateral knee pain would be much beneficial. Currently, size, shape and specific location of the symptomatic fabella are undefined.

\section{REFERENCES}

1. Ando $Y$, Miyamoto $Y$, Tokimura $F$, et al. A case report on a very rare variant of popliteal artery entrapment syndrome due to an enlarged fabella associated with severe knee osteoarthritis. J Orthop Sci. 2017; 22(1): 164-168, doi: 10.1016/j.jos.2015.06.025, indexed in Pubmed: 26740435.

2. Chew CP, Lee $\mathrm{KH}$, Koh JS, et al. Incidence and radiological characteristics of fabellae in an Asian population. Singapore Med J. 2014; 55(4): 198-201, indexed in Pubmed: 24763835.

3. Clarke AM, Matthews JG. Osteoarthritis of the fabella: a fourth knee compartment? J R Coll Surg Edinb. 1991; 36(1): 58, indexed in Pubmed: 2038004.

4. Crouch JE. Text-atlas of cat anatomy. Lea \& Fegiger Co, Philadelphia 1969: 10-50.

5. Dannawi Z, Khanduja V, Vemulapalli KK, et al. Arthroscopic excision of the fabella. J Knee Surg. 2007; 20(4): 299-301, indexed in Pubmed: 17993073.

6. Dashefsky JH. Fracture of the fabella: a case report. J Bone Joint Surg Am. 1977; 59(5): 698, indexed in Pubmed: 873972.

7. Duncan W, Dahm DL. Clinical anatomy of the fabella. Clin Anat. 2003; 16(5): 448-449, doi: 10.1002/ca.10137, indexed in Pubmed: 12903068.

8. Evans HE, Christensen GC. Miller's anatomy of the dog. 2nd Ed. Saunders, Philadelphia 1979: 205-215.

9. Franceschi F, Longo UG, Ruzzini L, et al. Dislocation of an enlarged fabella as uncommon cause of knee pain: a case report. Knee. 2007; 14(4): 330-332, doi: 10.1016/j. knee.2007.03.007, indexed in Pubmed: 17490883.

10. Frey C, Bjorkengen A, Sartoris D, et al. Knee dysfunction secondary to dislocation of the fabella. Clin Orthop Relat Res. 1987(222): 223-227, indexed in Pubmed: 3621725. 
11. Goldenberg RR, Wild EL. Chondromalacia fabellae. J Bone Joint Surg Am. 1952; 24 A(3): 688-690, indexed in Pubmed: 14946223.

12. lida $\mathrm{H}$, Arisawa $\mathrm{O}$, Yufu J, et al. A case of peroneal nerve palsy compression by the fabella. Orthop Surg. 1976(27): 299-302.

13. Kaplan E. The fabellofibular and short lateral ligaments of the knee joint. J Bone Joint Surg. 1961; 43(2): 169-179, doi: 10.2106/00004623-196143020-00002.

14. Kato Y, Yamauchi S. Atlas of comparative anatomy in domestic animals. Yokendo, Tokyo 2003: 128-163.

15. Kawashima T, Takeishi H, Yoshitomi S, et al. Anatomical study of the fabella, fabellar complex and its clinical implications. Surg Radiol Anat. 2007; 29(8): 611-616, doi: 10.1007/ s00276-007-0259-4, indexed in Pubmed: 17882346.

16. Larson JE, Becker DA. Fabellar impingement in total knee arthroplasty. A case report. J Arthroplasty. 1993; 8(1): 95-97, indexed in Pubmed: 8436997.

17. Levowitz B, Kletschka H. Fracture of the fabella. J Bone Joint Surg. 1955; 37(4): 876-877, doi: 10.2106/00004623195537040-00021.

18. Mangieri JV. Peroneal-nerve injury from an enlarged fabella. A case report. J Bone Joint Surg Am. 1973; 55(2): 395-397, indexed in Pubmed: 4696171.

19. Minowa T, Murakami G, Kura H, et al. Does the fabella contribute to the reinforcement of the posterolateral corner of the knee by inducing the development of associated ligaments? J Orthop Sci. 2004; 9(1): 59-65, doi: 10.1007/ s00776-003-0739-2, indexed in Pubmed: 14767706.

20. Moorman CT, LaPrade RF. Anatomy and biomechanics of the posterolateral corner of the knee. J Knee Surg. 2005; 18(2): 137-145, indexed in Pubmed: 15915835.

21. Mottershead S. Sesamoid bones and cartilages: An enquiry into their function. Clin Anat. 1988; 1(1): 59-62, doi: 10.1002/ca.980010110.

22. Munk PL, Althathlol A, Rashid F, et al. MR features of a giant cyamella in a patient with osteoarthritis: presentation, diagnosis and discussion. Skeletal Radiol. 2009; 38(1): 69, 91-69, 92, doi: 10.1007/s00256-008-0582-9, indexed in Pubmed: 18810436.

23. Newell RLM. Leg. In: Gray's Anatomy. 39th Ed. Elsevier Churchill Livingstone, Philadelphia, PA 2005: 1499.

24. Orhan IO, Haziroglu RM, Gultiken ME. The ligaments and sesamoid bones of knee joint in New Zealand rabbits. Anat Histol Embryol. 2005; 34(2): 65-71, doi: 10.1111/j.14390264.2004.00557.x, indexed in Pubmed: 15771666.

25. Phukubye $P$, Oyedele $O$. The incidence and structure of the fabella in a South African cadaver sample. Clin Anat. 2011; 24(1): 84-90, doi: 10.1002/ca.21049, indexed in Pubmed: 20830786.

26. Piyawinijwong S, Sirisathira N, Sricharoenvej S. The fabella, fabellofibular and short lateral ligaments: An anatomical study in Thais cadavers. Siriraj Med J. 2012; 64(Suppl 1): S15-S18.

27. Popesko P. Atlas of topographical anatomy of the domestic animals, vol. 3. 2nd Ed. WB Saunders Co, Philadelphia 1977: 5-205.

28. Pritchett JW. The incidence of fabellae in osteoarthrosis of the knee. J Bone Joint Surg Am. 1984; 66(9): 1379-1380, indexed in Pubmed: 6501334.

29. Raheem O, Philpott J, Ryan W, et al. Anatomical variations in the anatomy of the posterolateral corner of the knee. Knee Surg Sports Traumatol Arthrosc. 2007; 15(7): 895-900, doi: 10.1007/s00167-007-0301-4, indexed in Pubmed: 17641923.

30. Robertson A, Jones SCE, Paes $R$, et al. The fabella: a forgotten source of knee pain? Knee. 2004; 11(3): 243-245, doi: 10.1016/S0968-0160(03)00103-0, indexed in Pubmed: 15194103.

31. Sarin VK, Erickson GM, Giori NJ, et al. Coincident development of sesamoid bones and clues to their evolution. Anat Rec. 1999; 257(5): 174-184, indexed in Pubmed: 10597342.

32. Seebacher JR, Inglis AE, Marshall JL, et al. The structure of the posterolateral aspect of the knee. J Bone Joint Surg Am. 1982; 64(4): 536-541, indexed in Pubmed: 7068696.

33. Segal A, Miller TT, Krauss ES. Fabellar snapping as a cause of knee pain after total knee replacement: assessment using dynamic sonography. AJR Am J Roentgenol. 2004; 183(2): 352-354, doi: 10.2214/ajr.183.2.1830352, indexed in Pubmed: 15269024.

34. Silva J, Chagas CA, Torres D, et al. Morphological Analyisis of the Fabella in Brazilians. Int J Morphol. 2010; 28(1): 105-110, doi: 10.4067/s0717-95022010000100015.

35. Tabira Y, Saga T, Takahashi N, et al. Influence of a fabella in the gastrocnemius muscle on the common fibular nerve in Japanese subjects. Clin Anat. 2013; 26(7): 893-902, doi: 10.1002/ca.22153, indexed in Pubmed: 22933414.

36. Takebe K, Hirohata K. Peroneal nerve palsy cased by the fabella. Orthop Surg. 1981; 32: 1169-1174.

37. Takebe K, Kita K, Hirohata K. Radiological and anatomical observation on fabella. Orthop Surg: 1983; 34: 1163-1170.

38. Koda H, Takara K, Arimura K, et al. A case of peroneal nerve palsy caused by the fabella. Orthopedics Traumatol. 1989; 38(1): 304-307.

39. Tang JY, Mulcahy $\mathrm{H}$, Chew F. High-energy fracture of the fabella. Radiol Case Rep. 2010; 5(4): 454, doi: 10.2484/ rcr.v514.454, indexed in Pubmed: 27307881.

40. Theodorou SJ, Theodorou DJ, Resnick D. Painful stress fractures of the fabella in patients with total knee arthroplasty. AJR Am J Roentgenol. 2005; 185(5): 1141-1144, doi: 10.2214/AJR.04.1230, indexed in Pubmed: 16247123.

41. Weiner $D$, Macnab I, Turner M. The fabella syndrome. Clin Orthop Relat Res. 1977; 2(126): 213-215, indexed in Pubmed: 598120.

42. Weiner DS, Macnab I. The "fabella syndrome": an update. J Pediatr Orthop. 1982; 2(4): 405-408, indexed in Pubmed: 6815224.

43. Yu JS, Salonen DC, Hodler J, et al. Posterolateral aspect of the knee: improved MR imaging with a coronal oblique technique. Radiology. 1996; 198(1): 199-204, doi: 10.1148/radiology.198.1.8539378, indexed in Pubmed: 8539378.

44. Zeng SX, Dong XL, Dang RS, et al. Anatomic study of fabella and its surrounding structures in a Chinese population. Surg Radiol Anat. 2012; 34(1): 65-71, doi: 10.1007/ s00276-011-0828-4, indexed in Pubmed: 21626275. 